\title{
Energy Management Strategies in hydrogen Smart-Grids: A laboratory experience
}

\author{
L. Valverde ${ }^{a, *}$, F. Rosa ${ }^{b}$, C. Bordons ${ }^{c}$, J. Guerra ${ }^{b}$ \\ a AICIA, School of Engineering, 41092, Seville, Spain \\ b Energy Engineering Department, School of Engineering, University of Seville, 41092, Seville, Spain \\ c System Engineering and Automation Department, School of Engineering, University of Seville, 41092, Seville, Spain
}

\section{A R T I C L E I N F O}

Article history:

Received 6 March 2016

Received in revised form

25 May 2016

Accepted 29 May 2016

Available online $\mathrm{xxx}$

Keywords:

Smart Grid

Energy management

Power management

Hydrogen

Energy storage

Experimental

\begin{abstract}
A B S T R A C T
As microgrids gain reputation, nations are making decisions towards a new energetic paradigm where the centralized model is being abandoned in favor of a more sophisticated, reliable, environmentally friendly and decentralized one.

The implementation of such sophisticated systems drive to find out new control techniques that make the system "smart", bringing the Smart-Grid concept. This paper studies the role of Energy Management Strategies (EMSs) in hydrogen microgrids, covering both theoretical and experimental sides. It first describes the commissioning of a new labscale microgrid system to analyze a set of different EMS performance in real-life. This is followed by a summary of the approach used towards obtaining dynamic models to study and refine the different controllers implemented within this work. Then the implementation and validation of the developed EMSs using the new labscale microgrid are discussed. Experimental results are shown comparing the response of simple strategies (hysteresis band) against complex on-line optimization techniques, such as the Model Predictive Control. The difference between both approaches is extensively discussed. Results evidence how different control techniques can greatly influence the plant performance and finally we provide a set of guidelines for designing and operating Smart Grids.

๑ 2016 Hydrogen Energy Publications LLC. Published by Elsevier Ltd. All rights reserved.
\end{abstract}

\section{Introduction}

It is well known that the demand for energy, especially for electricity, has increased exponentially for years as a result of the industrial and technological development. In particular, developing countries are placing the global energy supply at risk position and are potentially leading to a global energy crisis $[1,2]$. It is clear that there is a need for increasing our energy supply, while at the same time we must be aware of its effects on the environmental and contribute to reducing global warming. Therefore, any new energy source has to be cleaner. Renewable Energy Sources (RES) are poised to be the solution that satisfies all parties. In fact, major countries are implementing new regulations that make the use of renewable sources mandatory. Twenty-nine states in the United States have already established mandates to generate between 20 and 33\% of their electricity from renewables by 2020 [3]. Likewise, the EU's 20-20-20 directive [4] is gradually being adopted in Europe. In addition to this, environmental regulations are restricting the use of coal based plants and after Fukushima accident some countries (such as Germany, Italy, Japan, Sweden, etc.) are limiting their nuclear programs.

\footnotetext{
* Corresponding author.

E-mail address: lvalverde@etsi.us.es (L. Valverde).
} 
As a result of these policies, RES have experienced a huge development. In particular, wind and solar energy are the most mature and widespread technologies, although not yet economically competitive. This low competitiveness is further reduced by the inherent intermittence of any renewable source. Indeed, the massive introduction of renewable energy into the electrical power system has unveiled two important challenges: One (challenge) is to maintain energy security for end-users; the other is to stabilize the electrical grid so as to avoid disconnections of wind farms and solar fields when there is strong surplus of RES and low demand [5]. The bridge to a sustainable energy future passes through the ability to transform uncontrollable power sources into dispatchable units. Therefore, Electrical Energy Storage (EES) must become an integral element of the renewable adoption strategy.

Indeed, R\&D strategies are funding a wide range of solutions for EES. Fig. 1 shows a "Ragone Chart" summarizing the different and most advanced electrical energy storage technologies. This chart is used to illustrate a performance comparison between EES. The specific power/energy of conventional internal combustion engines was added to the chart for further analysis. As it can be seen, fuel cells present high energy density and high power density, only overpassed by IC engines. Besides power and energy capabilities, hydrogen, as a storage medium, has received much attention because of its flexibility. Hydrogen differs from the conventional idea of energy storage in that it separates the hydrogen production, storage and use. Electrolyzers, which provide wind/solar peak shaving whereas producing hydrogen from water, become an attractive solution to RES penetration because they can provide bulk energy storage (Power-to-Gas). Then, at a peak demand, a fuel cell uses the hydrogen to quickly respond to loads and thus providing short-term energy deficit. In addition to being used in fuel cells, hydrogen production can be used for other purposes, such as fueling vehicles or it can be distributed through the gas grid [6].

As it has been stated, the underlying concept of storing excess energy to deliver it later on is very simple. However, there is a great technological challenge in the automation of the control system and the way it coordinates and manages the different equipment used within an RES to EES concept.

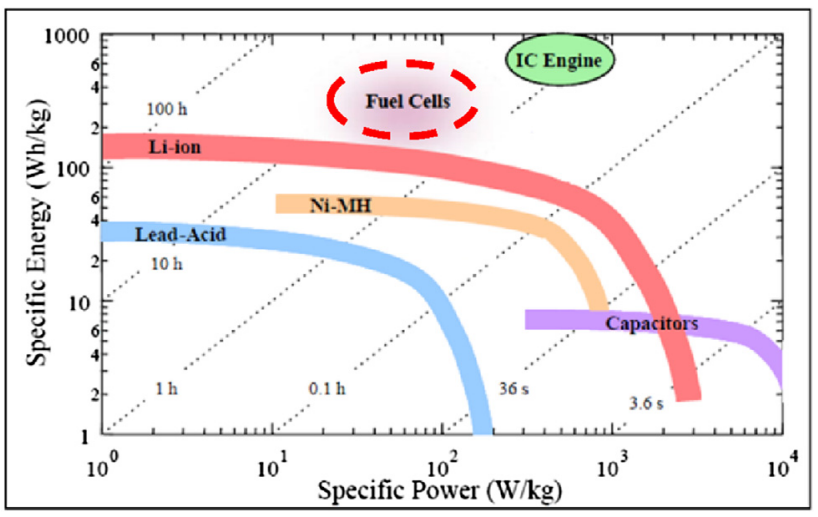

Fig. 1 - Energy storage technologies comparison. Source: Energy storage for power grids and electric transportation: a technology assessment [7].
Ultimately, and depending on the control strategy of the equipment, different performances can be obtained in the RES/EES plant performance.

An Energy Management Strategy (EMS) has to balance the power production from the renewable source and satisfy the demand by means of the energy storage. At the same time, ideally, an EMS would have to optimize the system efficiency and to minimize the operational cost. Despite the key roles that have been indicated, the fact is that in the past, EMSs for Smart-Grids (SGs) were quite simple and often neglected. It can be attributed to the pursuit of simplicity and/or the lack of previous experience. It is important to note that in SGs there is a substantial lack of experimental validation, which is essential to build confidence and acceptance on this technology both for industry experts and for public.

Further to the above, and after a decade of demonstration projects, operational experience has reinforced the idea that system performance is highly subjected to the control strategy and has not been up to the mark [8]. As literature on the subject points out, EMS is linked to the economic viability of the plant, since equipment lifetime is closely related to the way it is operated [9-11]. Therefore, challenges ahead are translated into innovative control strategies that can benefit efficiency and cost reduction to make this technology more competitive.

The aim of this paper is to bring the laboratory experience in the validation of Energy Management Strategies for SmartGrids, which incorporates renewable energy and hybrid energy storage based on hydrogen and batteries. This experience could be a valuable resource to build and scale-up future plants. Key findings were obtained through the achievement of a series of steps aimed towards optimization of Smart-Grids operation. First step was the commissioning of an experimental platform with flexibility to test a variety of controllers. This process is fully explained in Section HyLab: Smart-Grid laboratory system. Following this, it was necessary to characterize all the equipment in order to know their operational curves and parameters. The characterization results of static and dynamic behavior are described in Section Characterization of equipment dynamic and static behavior. Next step was to develop a set of models capable to replicate with sufficient accuracy the real system in order to simulate and refine EMSs. This step is depicted in Section Modelling tool. Finally, a deep study of EMSs is provided. The study covers from most basic operation modes to recent advances in optimal control strategies, such as Model Predictive Control. Section Operational results of Energy Management Strategies in the hydrogen Smart Grid fully covers this study while Section Lessons learned and experience remarks the experience gained and lessons learned. Final conclusions of this research are given in Section Conclusion and recommendations.

\section{HyLab: Smart-Grid laboratory system}

The motivation for the construction of the HyLab laboratory was the development of a versatile experimental facility that allows research to be performed on the integration of renewable energy with the hydrogen vector under a SmartGrid concept. 
The HyLab laboratory, at the University of Seville (Spain) was created in 2008. After several stages, the integrated system was commissioned in 2011 [12]. It has features that support the implementation and investigation of different modes of operation and control strategies. HyLab has a high degree of flexibility, achieved by means of electronic power and load which allow for emulating solar, wind, tidal or other RES as well as any demand profile, such as electric vehicles or households. Equipment can be isolated to the rest of the microgrid to be operated separately or to investigate different topologies as well as to perform specific test to characterize energy storage technologies and obtain the parameters to be used in modelling tasks. Each component is connected to a DC bus of $48 \mathrm{~V}$ by means of power converters. Hence, additional components can be added easily to the scheme.

The equipment main features are shown in Table 1 . It comprises of a $6-\mathrm{kW}$ programmable electronic source of $6-\mathrm{kW}$ to emulate the Renewable Energy Sources, a 1-kW PEM (Proton Exchange Membrane) electrolyzer for the production of hydrogen, a 7- $\mathrm{N} \mathrm{m}^{3}$ hydrogen storage tank, based on metal hydrides, a 367-Ah lead-acid battery bank, a 1.5-kW PEM fuel cell and finally a $2.5-\mathrm{kW}$ programmable electronic load to emulate different demand conditions. Thus, the configuration achieved is a renewable energy Smart-Grid (SG) based on hydrogen and batteries as energy storage.

The entire system is supervised by a PLC that receives all sensor signals and manages the actions of the valves and setpoints. HyLab has a Controlled Area Network (CAN) based communication system. The CAN bus enables controlling both fuel cell and power converters. As for the electrolyzer, it communicates with the central controller via OPC communication (Ole Process Control). Finally, a control computer has been installed in order to implement advanced controllers through Matlab environment that communicates with central PLC using the OPC communication as well.

Fig. 2 shows a block diagram of the system. In this scheme, only two converters are required (corresponding to the electrolyzer and the fuel cell) due to the fact that the power electronics associated with the renewable source and load are electronically emulated. The bus voltage is held by the battery bank, directly connected to the bus. The bus voltage is stable around $48 \mathrm{~V}$ (depending on the battery state of charge). A SCADA control system receives the current state of the overall system and provides data recording, managing and system configuration, in addition to overseeing the entire process. The main equipment to be controlled is the DC/DC converters,

Table 1 - Hydrogen microgrid equipment.

\begin{tabular}{lll} 
Equipment & Rated capacity & Manufacturer \\
\hline Electronic power source & $6 \mathrm{~kW}$ & POWERBOX \\
Electronic load & $2.5 \mathrm{~kW}$ & AMREL \\
PEM electrolyzer & $0.23 \mathrm{Nm}^{3} / \mathrm{h} @ 1 \mathrm{~kW}$ & HAMILTON-STD \\
Metal hydride tank & $7 \mathrm{Nm}^{3}, 5 \mathrm{bar}$ & LABTECH \\
PEM FUEL CELL & $1.5 \mathrm{~kW} @ 20 \mathrm{Nl}$ & MES-DEA \\
Lead-acid battery bank & $\mathrm{C}_{120}=367 \mathrm{Ah}$ & EXIDE \\
Water purification & $3 \mathrm{~L} / \mathrm{h} @ 15 \mathrm{M} \Omega$ & MILLIPORE \\
PLC & M340-Canbus & SCHNEIDER \\
DC-DC converters & $1.5 \mathrm{~kW}, 1 \mathrm{~kW}$ & WIN INERTIA \\
\hline
\end{tabular}

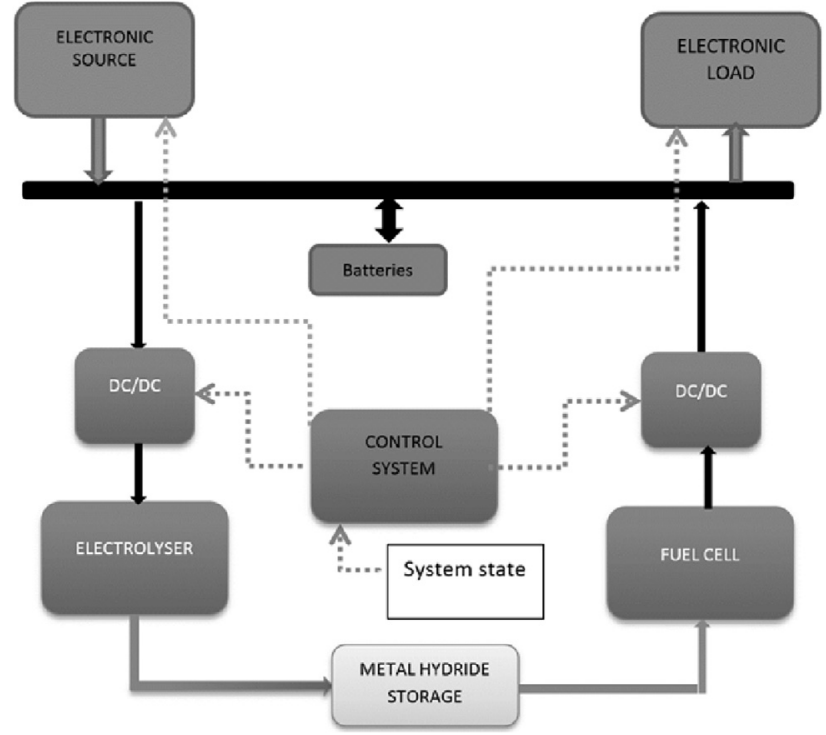

Fig. 2 - Diagram of the Smart-Grid laboratory system showing electrical and control architecture.

which provide the power references for the electrolyzer and the fuel cell.

\section{Characterization of equipment dynamic and static behavior}

The proper characterization of the equipment is an extremely important task when designing and operating microgrids. Equipment characterization aims at obtaining the electrical curves, operational limits, representative parameters, thermal behavior, performance, efficiencies, time constants, etc. Not to mention that the equipment characterization allows for the experimental validation and mathematical model development, that will be presented in the next section. It should be noted that the characterization of the equipment is essential to define the parameters and characteristic curves for a successful outcome of this work.

\section{Electrolyzer static characterization}

In order to obtain the electrical characteristic curve and parameters, the following test was conducted: we used the laboratory electrolyzer SPE hydrogen-HAMILTON 1-kW PEM. Using the programmable electronic source and data acquisition system installed at the laboratory, the test began by applying a current of 5-A. This current is increased gradually in steps of 5-A after a necessary elapsed time for voltage and current stabilization. The maximum current applied to the stack was 70-A. At this point, we repeated the test in opposite way, by decreasing the current in steps of 5-A to analyze the hysteresis behavior. Stack voltage data were recorded at onesecond sample time. The results of the static characterization (polarization curve) are shown in Fig. 3.

A minimum current is necessary for safe operation of the electrolyzer. In this case, the electrolyzer is not operated below 5-A to avoid gas mixtures. In the results shown in Fig. 3, 


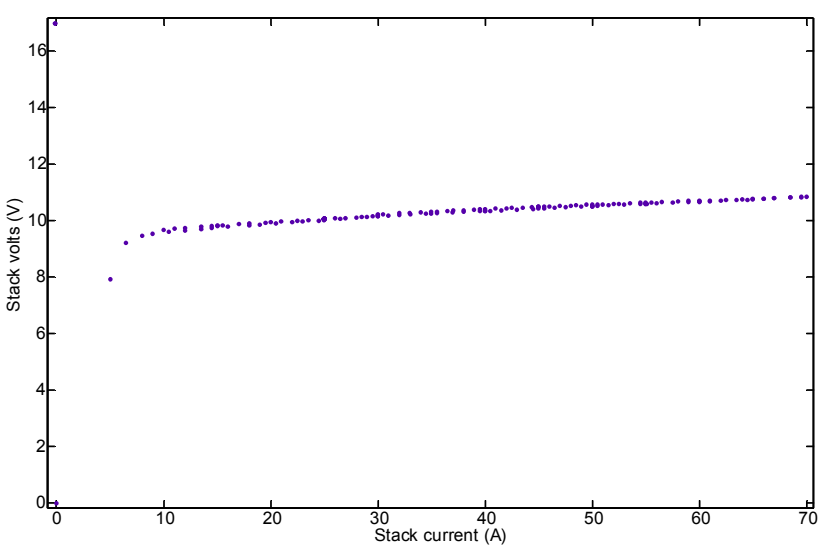

Fig. 3 - Electrolyzer polarization curve obtained at $26^{\circ} \mathrm{C}$.

it can be observed a fast increase in voltage, then a stabilization of the voltage increase. It was not observed a remarkable hysteresis effect in this test for the polarization curve.

\section{Electrolyzer dynamic characterization}

In this test, the electrolyzer was subjected to a ramp input in power consumption. The test was conducted over a period of $50 \mathrm{~min}$ in order to have sufficient time to capture the electrolyzer thermal dynamics. Electrolyzer thermal inertia depends upon many factors, such as the heat generated in the electrolysis process and the isolation and heat losses, as it will be explained in Section PEM electrolyzer (EZ). It is worth pointing out that characterization is frequently the only way to find out unknown parameters that are part of the manufacturer's know-how and consequently are not frequently disclosed. In Fig. 4 it can be observed the test results, showing the temperature evolution with the power input.

\section{Fuel cell static characterization}

Fuel cell characterization tests follow the same approach presented above. The objective is to obtain the polarization curve (voltage-current relationship). In this test, the fuel cell was subjected to an increasing load demand to map all the

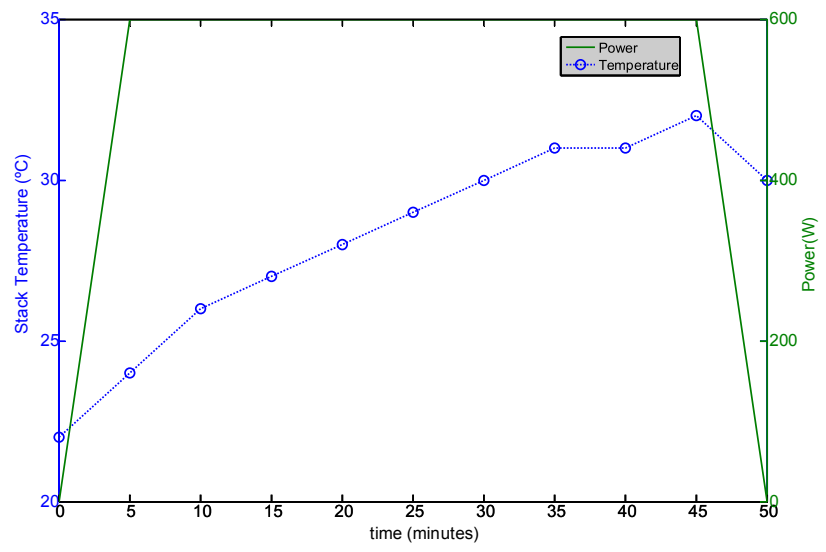

Fig. 4 - Evolution of the electrolyzer stack temperature in the dynamic test. operating points. Under a safe and controlled test environment, the power produced by the fuel cell is gradually increased. This is achieved by increasing the value of a load resistor in steps until the maximum power output of the fuel cell is reached. Samples are recorded each two minutes giving enough time to reach the steady state conditions at each sample point. Uncertainties in measures were observed in the experiment, as it is shown in Fig. 5. Especially, at high power values. This can be partly attributed to temperature variations during the experiment and the difficulty to maintain stable power by the fuel cell. In spite of these uncertainties, the polarization curve was identified.

Notice that in the test shown in Fig. 5 the power reached by the fuel cell was $1813 \mathrm{~W}, 21 \%$ higher than the rated power of $1.5 \mathrm{~kW}$ stated in Table 1 . This is explained because the limits established by the manufacturer are in voltage. Then, in case of under voltage (36 V), the fuel cell and the load automatically stop the operation to prevent cell damage. As the test demonstrated, nominal power of the fuel cell is $1.5 \mathrm{~kW}$ although it was able to provide up to $1.8 \mathrm{~kW}$.

\section{Fuel cell dynamic characterization}

Once the static behavior is accurately characterized, a dynamic test was performed. For this test, a power profile which clearly varies with time was used in order to highlight the different operation zones of the fuel cell (Fig. 6). The results will be valuable to validate the thermal model of the fuel cell. By direct connection of the electronic load and the fuel cell, the following results were obtained:

Different power profiles can be used as long as the temperature changes are obtained. In the test presented in Fig. 6 a random profile was used. It is recommended to first increase the power, stabilize and then decrease, in order to identify the thermal capacity of the system.

\section{Modelling tool}

A number of simulation tools are available nowadays for the analysis of hydrogen-based energy systems and Smart-Grids, such as HOMER, HYBRID2 or HOGA [13]. These tools are

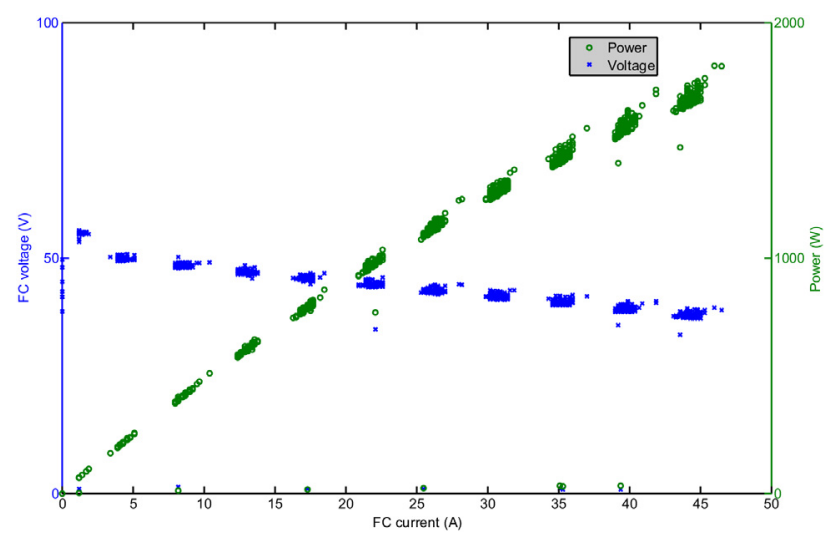

Fig. 5 - PEM fuel cell static characterization showing voltage-current and power data. 


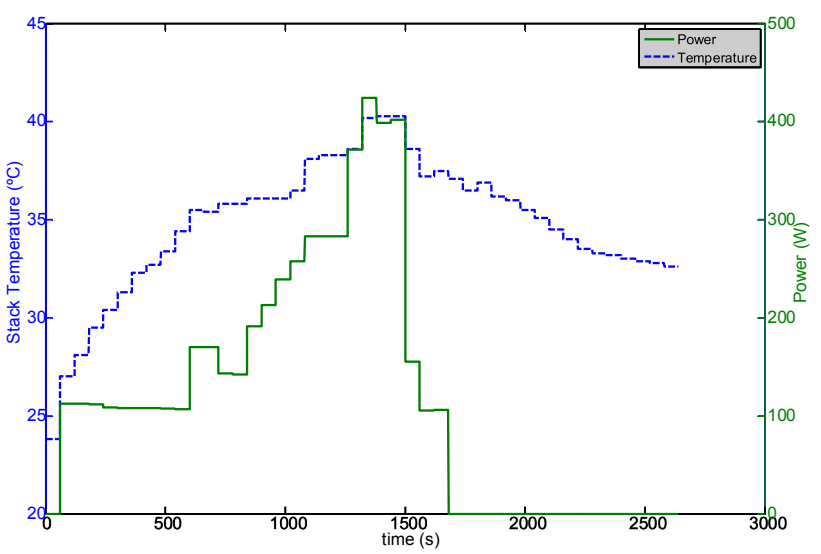

Fig. 6 - Fuel cell dynamic test showing the evolution of the stack temperature and power generated in a dynamic test.

useful for design or analysis. However, the flexibility of these tools is limited and they might not be suitable to develop an in-deep research for control strategies and Smart-Grids optimization.

A complete SG model was developed focusing on dominant dynamics. For instance, stack temperature in the fuel cell and the electrolyzer strongly influences their performance; metal hydride thermal behavior is the main responsible of the hydrogen absorption/desorption kinetics; and battery charging/discharging dynamics have a remarkable influence on the state of charge and lifetime.

To illustrate main components modelled and their features, Table 2 summarizes the approach for the dynamics considered in the Smart-Grid model.

Detailed description of each equipment modelling is out of the scope of this paper and it can be found in Ref. [14]. Nevertheless, main equations, references and guidelines will be provided in the following sections for replicability.

As for the validation, the methodology used here is based on the following logical approach: in the first step, experimental data are collected from the pilot plant operation and processed. A set of input-output values is grouped with respect to constant values of temperature (steady-state validation). The next step is to find out the parameters for the voltage-current curve. Once electrical behavior is validated, the thermal model, which depends on external conditions such as natural convection, etc., is fitted. Each Smart Grid model is succinctly described below:

\section{Wind turbine (WT)}

Wind turbine models can be divided into detailed models [15] (which involve a high number of parameters, electrical and mechanical dynamics) and into simplified models [16], which may only rely on the power curve in most simple cases. For the laboratory microgrid we have proposed an intermediate solution. This solution is based on using the power curve and a transfer function to model the rotor dynamics [17]. The transfer function for the WT dynamics is shown in equation (1).

$\frac{P_{g}}{P_{w t}}=\frac{0.25}{s^{2}+0.707 s+0.25}$

\section{Photovoltaic panel (PV)}

In the literature, we found several PV models which allow for the prediction of power output, usually based on the equivalent circuit [18]. These models consider solar cells as an equivalent electric circuit with radiation and temperature dependency as it is shown in equations (2) and (3). The most widely used equivalent circuit has five parameters [19]. This model has been implemented in this paper.

$I=I_{L}-I_{0} \exp \left(\frac{V+I R_{s}}{m V_{t}\left(T_{F V}\right)}-1\right)-\left(\frac{V+I R_{s}}{R_{p}}\right)$

$\frac{d T_{F V}}{d t}=-\frac{1}{300} T_{F V}+\frac{1}{300} T_{a m b}+\left(T_{N O C}-293.15\right) \frac{G}{2400}$

PEM electrolyzer (EZ)

The electrolysis process is possible when a differential of potential is held between the anode and the cathode. This potential is expressed in the equation (4), where: $V_{o}$ is the reversible potential that depends on temperature and gas partial pressures and the following three terms ponder the electrode's overpotential, ohmic losses and ion transport respectively. To complete the model, the energy balance, expressed in equation (5) allows us to calculate the heat generated in the electrolyzer stack $(\dot{Q})$, which highly affects the hydrogen production [20]. In this equation, $\dot{Q}_{\text {ely }}$ is the heat generated in the electrolysis process, $\dot{Q}_{\text {loss }}$ are the heat losses to the environment and $\dot{Q}_{\text {cool }}$ represents the heat evacuated by the electrolyzer cooling system.

$\mathrm{V}_{\text {cell }}=\mathrm{V}_{0}+\eta_{\text {etd }}+\eta_{\text {ohm }}+\eta_{\text {ion }}$

$\dot{Q}=\dot{Q}_{\text {ely }}-\dot{Q}_{\text {loss }}-\dot{Q}_{\text {cool }}$

\section{Metal hydride hydrogen storage (MH)}

MH is a complex alloy that permits the storage of hydrogen at low pressure. Due to the complexity of such system, to enable whole system-scope SG model, we have implemented a zerodimensional model [14]. The charging and discharging processes were modelled and validated separately. The heat transfer governs the reaction kinetics both in the discharging and charging process and it is closely related to the amount of hydrogen released/stored, ultimately responsible of the metal

Table 2 - Approach for modelling the Smart Grid system.

SG component

Photovoltaic panel

Wind turbine

PEM electrolyzer

PEM fuel cell

Metal hydride storage

Battery bank

DC/DC converters
Main model characteristic

Five parameters model basis Inertia dynamics Thermal dynamics Thermal dynamics Pressure and thermal dynamics Charging/discharging dynamics Static 
hydride hydrogen content. This hydrogen content has been called Metal Hydride Level (MHL). Main parameters of the model are the heat transfer coefficient and the metal hydride enthalpy of formation. Through specific test performed in the SG laboratory, these parameters were found to be 2737$\mathrm{W} \mathrm{m} \mathrm{m}^{-2} \mathrm{~K}^{-1}$ and $30-\mathrm{kJ} \mathrm{mol}{ }^{-1}$, respectively. The model developed for the SG was adapted from Ref. [21].

\section{Fuel cell (FC)}

The PEM fuel cell modelling can be breakdown into an electrochemical submodel (which is static) and the thermal submodel (which is dynamic). Here also, the energy balance is used to calculate the stack temperature changes with time. As it can be seen in Fig. 7 the model prediction is close to the experimental results.

\section{Lead-acid battery model}

Battery modelling is a topic extensively discussed in the literature. The Lead-acid battery model was developed using the traditional scheme presented in Ref. [22]. This scheme incorporates an equivalent circuit that has an internal resistance and a controlled voltage source. We found that this model is able to calculate the battery external voltage and state of charge close to the reality.

The completed model was implemented using MatlabSimulink $^{\circledR}$ software. Once each piece of equipment was modelled and validated, exchange variables such as hydrogen production, battery state of charge, hydrogen demanded by the fuel cell, power demanded and generated by the renewable source, etc. were interconnected. Then, we tested the global state variables, such as the bus voltage or the hydrogen inventory in the integrated model and we found that the global plant matched the model prediction with a maximum error less than $4 \%$. Since they matched, we confirm that the tool is reliable. With this reliable simulation tool, we were able to proceed to the study of Energy Management Strategies. For further reading, the complete laboratory modelling and validation process is described in Ref. [14].

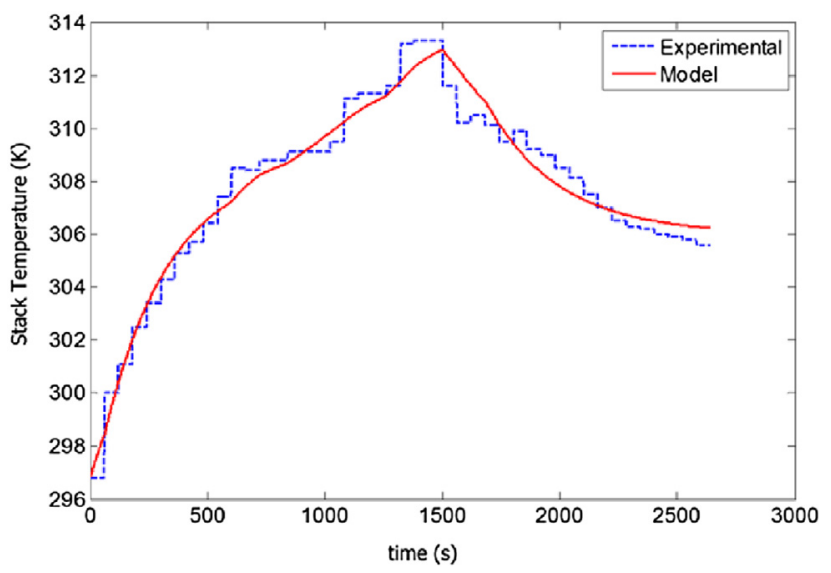

Fig. 7 - Validation of the fuel cell model. Comparison of stack temperature predicted by the model and experimental data gathered. Test conducted in controlled environment @ $25^{\circ} \mathrm{C}$.

\section{Operational results of Energy Management Strategies in the hydrogen Smart Grid}

To facilitate the presentation of the EMSs, a scheme of a typical microgrid centralized control system is presented with the different control levels from a general point of view. The primary objective of the EMS is to effectively balance the power in the microgrid to deliver electrical power to its local customers. Additionally, depending on the control algorithm, the EMS will try to optimize the energy production towards an assigned objective(s) [23].

The central energy management system, presented in Fig. 8, tackles the problem of Smart Grid planning establishing the equipment set-points according to availability of renewable resources and storage capacity. The EMS algorithms range from simple "if" rules to complex multiparameters optimization that can include the forecasting of electricity prices, loads, weather, operational cost, degradation issues, etc. [24-26]. In addition, the techno-economic optimization can be on-line or off-line depending on the computational burden required. Typically, the forecasting tasks are executed off-line by means of Neural-Networks $[27,28]$, although it can be implemented on-line [29]. This leads to separated schedules in EMS for Smart Grid that can be classified in: Long-term management (in the order of days) and short-term schedule (in the order of hours). Further, these two main levels can be also divided in more time scales:

- Long-term schedule:

Day management: Electricity market, load forecasting, RES prediction, $\mathrm{CO}_{2}$ emissions.

Hourly management: load sharing, energy storage availability.

- Short-term schedule:

Power management (interval of seconds): equipment dynamics, operation and maintenance costs, equipment lifetime.

Regulation service (interval of milliseconds): Power quality, frequency control, voltage control.

Although hydrogen energy is better suited for long-term energy storage. This is not in conflict with Short-term schedule since the electrolyzer can be working during hours while the control is sampling each second to properly balance the renewable power. Thus, in case of cloud is passing over the solar panels, a fast fluctuation can be immediately balanced.

Long-term EMS are nevertheless recommended for planning the electrolyzer switching on/off for example, in order to provide a guidance for the short-term controller.

This paper focuses on short-term, power/energy management strategies. The problem formulation in this framework is to calculate the power set-points for the electrolyzer, the fuel cell and the power exchanged with the grid. 


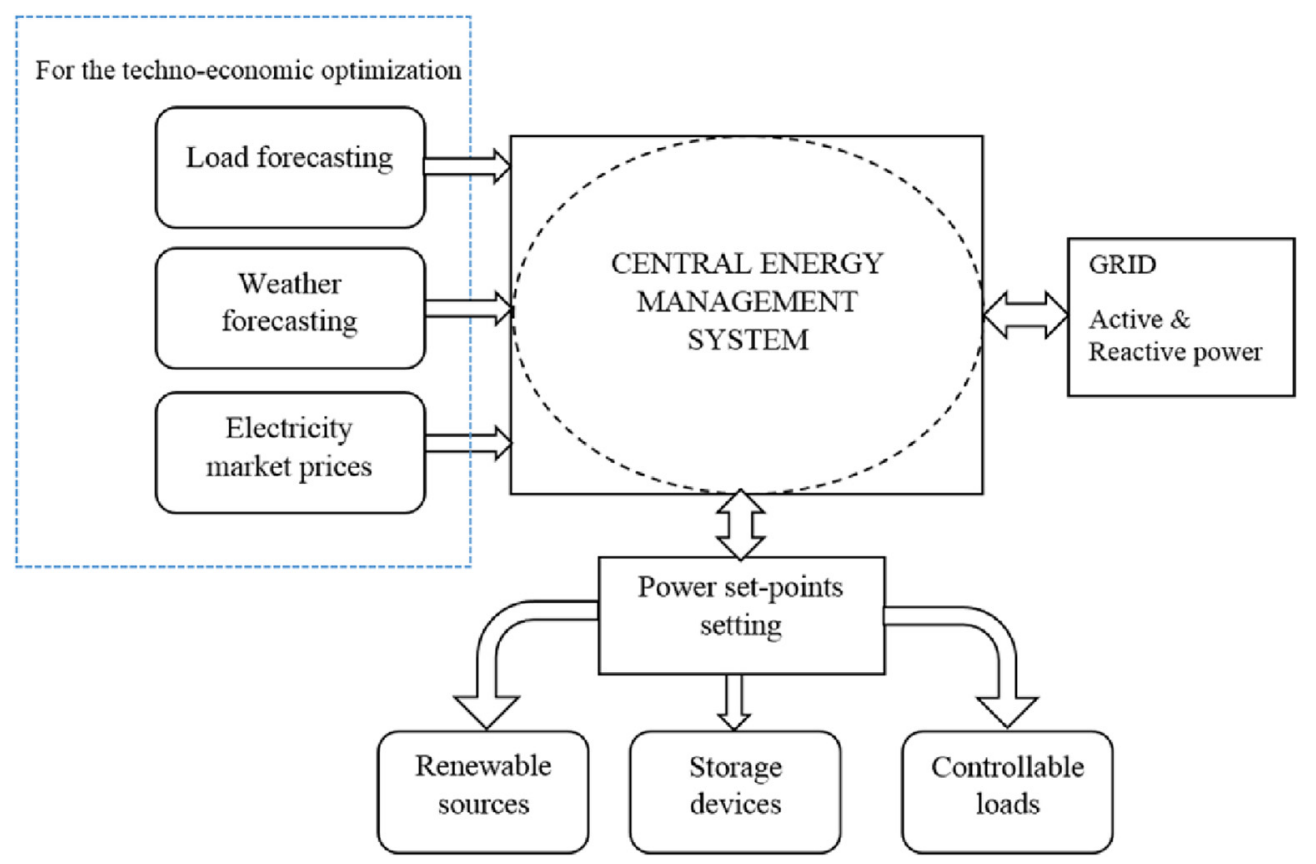

Fig. 8 - Architecture of a centralized EMS including optimal schedule and real-time power dispatch.

The following section aims to methodically classify the main techniques for power management applied to SGs. We have proposed the following three points to classify the EMSs:

\section{Hysteresis band control (HB)}

Hysteresis band control is defined as a set of algorithms designed through heuristic rules to handle the energy mismatch in the microgrid. Usually are characterized for being simple and reliable. This fact has made this technique the most popular for being implemented in real systems, according to [8]. The operation of the electrolyzer and the fuel cell follows a hysteresis band which thresholds are defined according to the state of charge of energy storage units. The complexity of the algorithms increases as more rules are added [30-32]. Then, in the presence of several energy storage system (such as ultracapacitors or flywheels), the criterion is to use several hysteresis band, each one inside the other, and always use first the system with higher efficiency.

\section{Artificial neural networks (ANN) and fuzzy logic}

This approach is used when the addition of heuristic rules becomes difficult to handle. "Linguistic rules" used in fuzzy logic can simplify the management and control of the microgrid, then, providing a suitable and practice solution. In this formulation, fuel cell and electrolyzer can achieve a variety of operation regimes (such as working at partial load or steady power), allowing the system to achieve higher efficiency. By means of feed-forward neural network or other "intelligent" algorithms, the control presumes knowledge of the future that can help to enhance the performance of the plant [33-36].

\section{Optimal control strategies}

By using single or multi-objective mathematical optimization, recent EMSs achieve the most advanced and complex level for shifting the renewable power. These techniques enable to include in the system operation a wide range of cost functions and parameters to encompass optimization techniques and realistic constraints. As previously pointed out, the problem formulation can include operation costs, equipment lifetime, emissions concerns, spot-market price, availability of hydrogen, etc.

Among optimal controllers, Model Predictive Control (MPC) has been recently demonstrated as a successful approach for energy management [37-41].

MPC solves an optimization problem each sampling time to determine minimal running cost while meeting the demand and considering technical and physical limits. MPC explicitly includes minimization of utilization cost in the formulation. In addition, it provides a framework to handle multivariable systems with a high number of constraints in a simpler manner, as is the case of hydrogen microgrids.

Despite MPC gaining a great reputation for hydrogen Smart-Grid control, still, there is a lack of experimental validation, specially, if we compare with the HB control. Thus, there is a need of further work in demonstrating EMSs.

\section{Operational results}

As shown above, each EMS group offers advantages and disadvantages. Most simple strategies, such as hysteresis band has demonstrated high reliability and easy implementation. A drawback is that the efficiency of the plant operation is far from optimal, that is why other techniques have received much attention. In contrast, optimal controllers, such as MPC have the potential of increased performance, accounting for 
cost reduction and increased efficiency. However, the implementation of an optimal control in a real time system poses many challenges. In particular, the computational requirements can be an issue due to fast changes in RES power.

In this work, we have tested the hysteresis band control and the Model Predictive Control techniques, in order to show and compare the capabilities of each strategy for Smart Grid energy management in a controlled laboratory environment.

The EMSs were tested in different weather conditions (sunny day, cloudy day, windy day, etc.) and different demand profiles. Below, two representative examples of the experiments conducted are shown. In both cases, the same PV and demand profiles are used. Solar energy generated reaches $15.9 \mathrm{kWh}$, while the day demand is $14.7 \mathrm{kWh}$ for both case studies.

1) Case study: hysteresis band (HB) control.

Fig. 9 shows the test results of the hysteresis band control, running under the operation mode called "Load following". This operation mode follows the power demand, shifting the excess energy, first to the battery bank, and second to the hydrogen path. All equipment is operated at "partial load mode". When the electrolyzer or the fuel cell are unable to meet the excess or defect of power, the grid is used to import/ export power. The activation of the fuel cell and the electrolyzer is controlled and based on the battery State of Charge (SOC). For this case, it has been set a minimum SOC threshold of $40 \%$ to activate the fuel cell and a maximum of $75 \%$ to activate the electrolyzer. These thresholds have been found to be the best option carrying out simulations to minimize the number of equipment start-stops.

In this test, the electronic source emulates a PV field of 2968 $\mathrm{W}_{\mathrm{p}}$ in good irradiance conditions (up to $1000 \mathrm{~W} / \mathrm{m}^{2}$ ). The EMS uses the battery bank as first medium to store power since their efficiency is higher than the hydrogen path. When the SOC reaches $75 \%$, the EMS worked successfully activating the electrolyzer. In this case, the electrolyzer worked at variable power, and the remaining excess is exported to the grid. At around $18.00 \mathrm{~h}$ when the sunset happens, the energy demand is much higher, causing the SOC drops till the lower threshold, activating the fuel cell to meet the demand.

\section{2) Case study: Model Predictive Control (MPC) strategy}

A Model Predictive Controller framework for microgrid management was developed in Ref. [37]. This controller has been implemented in the laboratory test bench to evaluate its performance. The experiment results are shown in Fig. 10. First of all, it should be highlighted that the experiment was successful. This is one of the scarce validations of advanced controllers in real environment.

The description of the experiment is similar to the hysteresis band till the activation of the electrolyzer (EZ) at 75\% SOC. At this point, there is a remarkable difference in the plant operation. The electrolyzer power consumption increases gradually, as the figure shows. Notice that, the algorithm evaluates the cost of electricity export (penalties and benefits) on one hand, and takes into account the electrolyzer degradation for a sudden power change, to progressively increase the power shifted to the electrolyzer. Some excess energy is sold to the grid and gradually decreases as the electrolyzer consumes more power. This reduces the energy dumped to the grid providing peak-shaving and reducing grid congestion in comparison with a system without electrolyzer.

The main difference is that in this case, the power derived to the electrolyzer is the optimal according to the cost function design of [37], that takes into account equipment constraints in terms of limits of power rates while optimizing efficiency, lifetime, and O\&M cost. It can be observed a
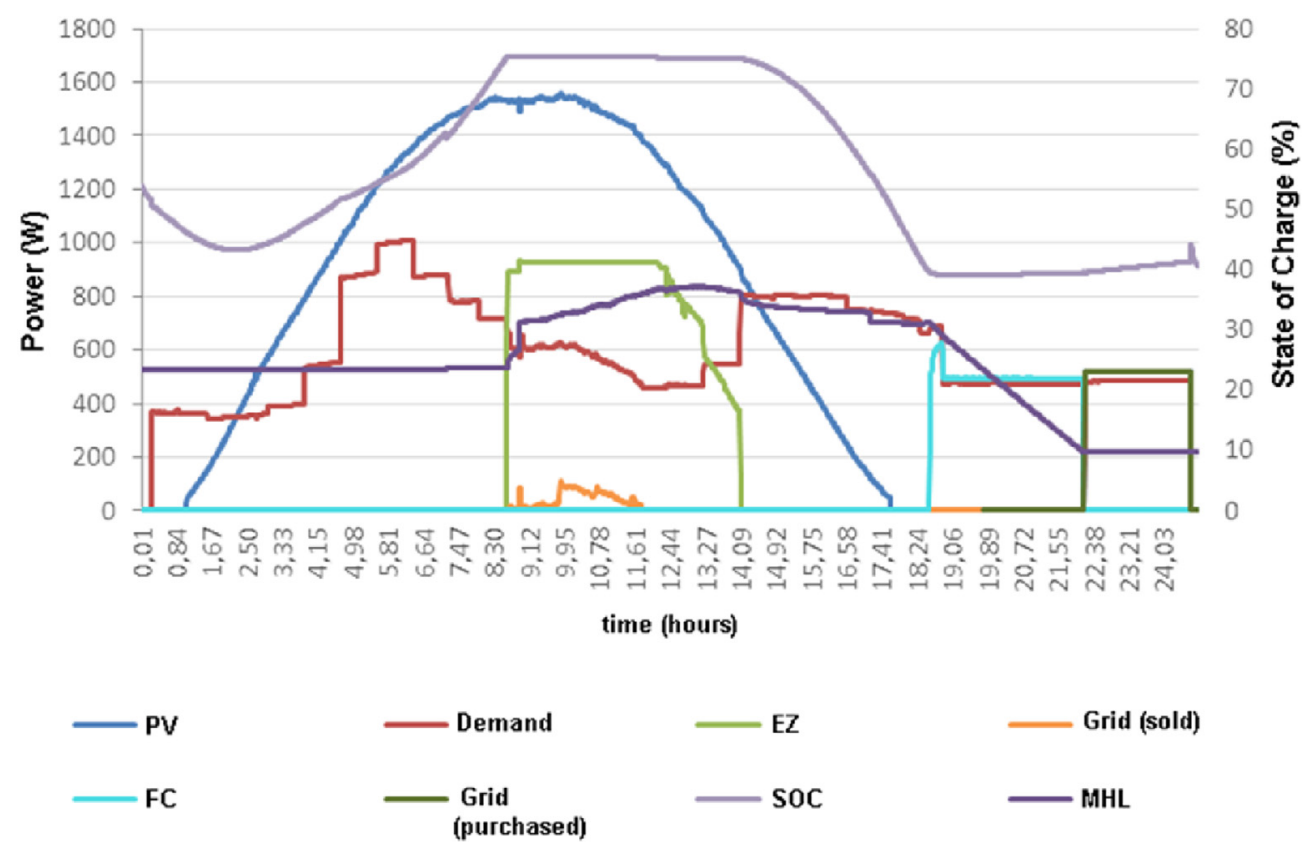

Fig. 9 - Experimental results of the SG operation under hysteresis band control (Operation mode: "load following"). 


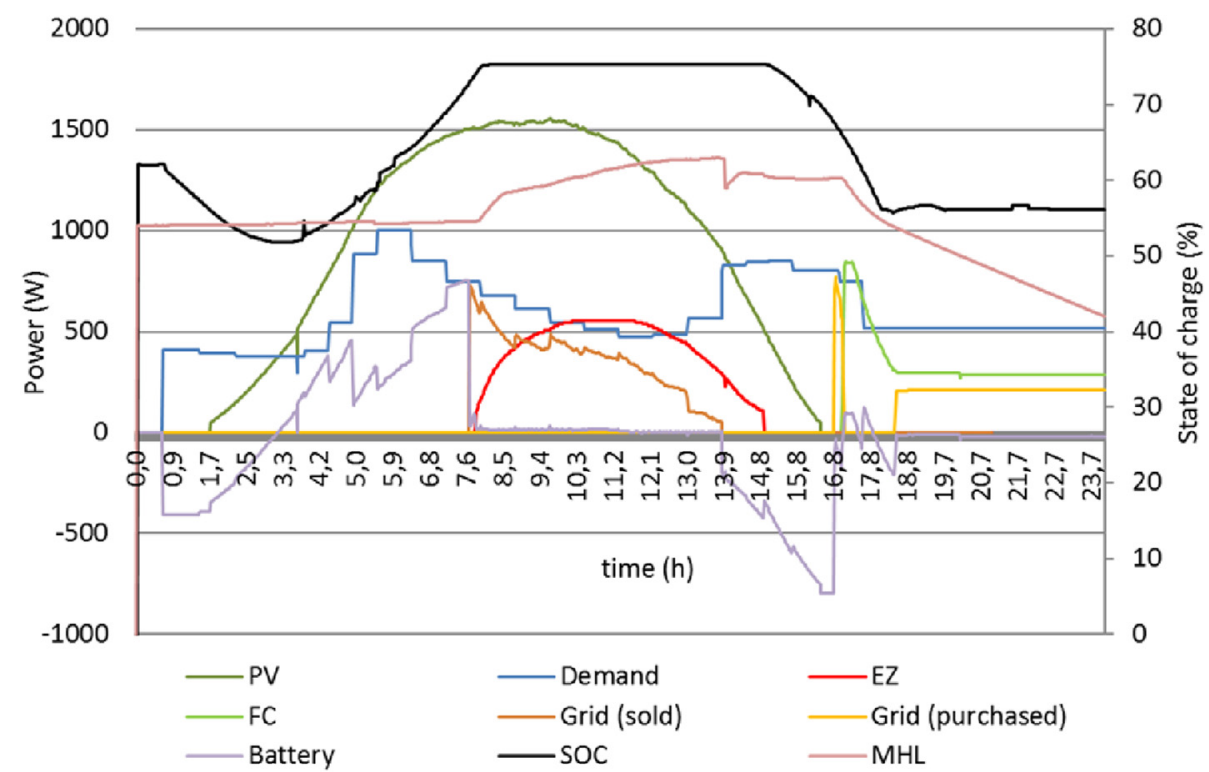

Fig. 10 - Experimental results of SG operation under MPC strategy.

smooth electrolyzer operation that is expected to increase the equipment lifetime while the grid absorbs peak power. The fuel cell operation follows a similar pattern, according to the design made. The power demanded is partially compensated by the grid, which assumes the peak power, while the fuel cell meets the energy demand according to the economic optimal. The controller respects the equipment power rate constraints imposed as well as providing the optimal economic dispatch.

\section{Lessons learned and experience}

After eight years since HyLab creation, several important experiences have been gained from the planning, building, and operation of the HyLab laboratory. As mentioned above, the equipment characterization and parameter estimation was essential for project success. Some issues were detected with the fuel cell, mainly related to internal water management. In days with high relative humidity, the loss of power was significant. Moreover after eight years of operation one of the cell resulted irreversibly damaged. In contrast, the PEM electrolyzer used demonstrated very high reliability. Even operating at partial load under high demanding profiles such as wind or cloudy days.

Regarding the storage devices, it was detected a remarkable loss of capacity in the lead-acid battery bank, up to $50 \%$ of the initial capacity, while in the metal hydride tank it was not detected any loss of its initial storage capacity. MH demonstrated to be a good choice from the technical and safety point of view since compression is avoided and it can be stored a low pressure indoor. On the other hand $\mathrm{MH}$ requires proper thermal management to deliver a minimum pressure for the fuel cell operation. In addition, it has to be taken into account the difficulties for estimating the hydrogen content inside the tank. Being the state-of-charge of both $\mathrm{MH}$ and batteries such an important parameter for control, it is a key issue to solve in future developments.

On the comparison of Energy Management Strategies, in the extensive experience of multiple EMSs tested at HyLab, MPC exhibited improved performance for all the situations and weather conditions. However, it has to be said that the optimality is not always satisfied, although infrequent, but incurring in some suboptimal solutions or not reaching a solution might happen. Therefore, the reliability of Hysteresis Band techniques should not be ignored, taking into account that lower efficiency and performance is achieved.

\section{Conclusion and recommendations}

We have presented in this paper the results of laboratory experience on Energy Management Strategies for hydrogen Smart Grids. A unique laboratory environment, specifically designed for testing control strategies, has been presented. The detailed equipment characterization was essential for the success of this project. Especially, to obtain realistic models which has enable accurate testing of the controllers before being implemented in the real plant. EMSs have been investigated and validated successfully on the experimental microgrid located at the University of Seville. The benchmarking of experimental results has pointed out that MPC is able to optimize the Smart Grid operation economically while respecting equipment constraints, which is expected to contribute to a higher equipment lifetime and reduced operational costs. The experiments have also evidenced how this cost reduction is achieved by a smooth operation of expensive equipment such as electrolyzer and fuel cell.

Future work will focus on developing and testing new variants of MPC for energy management in order to continue optimizing the plant operation. 


\section{Acknowledgments}

The authors acknowledge Spanish Ministry of Economy and Competitiveness for funding this work under the project DPI2013-46912-C2-1-R.

We would also like to express our appreciation to the reviewers for their comments that have contributed to the paper improvement.

\section{Nomenclature}

PV Photovoltaic field

Demand Power demanded

EZ Electrolyzer

Grid Utility Grid

FC Fuel cell

SOC Battery State-of-Charge

MHL Metal hydride Level

RES Renewable Energy Source

EES Electrical Energy Storage

EMS Energy Management Strategy

CAN Controlled Area Network

PLC Programmable Logic Controller

OPC Ole Process Control

PEM Proton Exchange Membrane

\section{REFERENCES}

[1] Information USE, Administration. Annual energy outlook 2015. 2015.

[2] Andrews J, Shabani B. Re-envisioning the role of hydrogen in a sustainable energy economy. Int J Hydrogen Energy 2012;37:1184-203. http://dx.doi.org/10.1016/ j.ijhydene.2011.09.137.

[3] US EPA Clean Energy Program. Air emissions. 2013.

[4] European Parliament. Directive 2012/27/EU of the European Parliament and of the Council of 25 October 2012 on energy efficiency. Off J Eur Union Dir 2012:1-56. http://dx.doi.org/ 10.3000/19770677.L_2012.315.eng.

[5] Gutiérrez-Martín F, Guerrero-Hernández I. Balancing the grid loads by large scale integration of hydrogen technologies: the case of the Spanish power system. Int J Hydrogen Energy 2012;37:1151-61. http://dx.doi.org/10.1016/ j.ijhydene.2011.09.116.

[6] Bennoua S, Le Duigou A, Quéméré M-M, Dautremont S. Role of hydrogen in resolving electricity grid issues. Int J Hydrogen Energy 2015;40:7231-45. http://dx.doi.org/10.1016/ j.ijhydene.2015.03.137.

[7] Parfomak PW. Energy storage for power grids and electric transportation: a technology assessment. Congr Res Serv Tech Rep R 2012:146.

[8] Valverde L, Ali D, Abdel-Wahab M, Guerra J, Hogg DF. A technical evaluation of wind-hydrogen (WH) demonstration projects in Europe. Power Eng Energy Electr Drives (POWERENG) 2013:1098-104. http://dx.doi.org/10.1109/ PowerEng.2013.6635764. Fourth Int Conf 2013.

[9] Zakrisson E. The effect of start/stop strategy on PEM fuel cell degradation characteristics. 2011. p. 47.

[10] Tesfahunegn SG, Ulleberg $\varnothing$, Vie PJS, Undeland TM. Optimal shifting of photovoltaic and load fluctuations from fuel cell and electrolyzer to lead acid battery in a photovoltaic/ hydrogen standalone power system for improved performance and life time. J Power Sources 2011;196:10401-14. http://dx.doi.org/10.1016/ j.jpowsour.2011.06.037.

[11] Chen H, Pei P, Song M. Lifetime prediction and the economic lifetime of proton exchange membrane fuel cells. Appl Energy 2015;142:154-63. http://dx.doi.org/10.1016/ j.apenergy.2014.12.062.

[12] Valverde L, Rosa F, Bordons C. Design, planning and management of a hydrogen-based microgrid. Ind Inf IEEE Trans 2013;9:1398-404. http://dx.doi.org/10.1109/ TII.2013.2246576.

[13] Bernal-Agustín JL, Dufo-López R. Simulation and optimization of stand-alone hybrid renewable energy systems. Renew Sustain Energy Rev 2009;13:2111-8. http:// dx.doi.org/10.1016/j.rser.2009.01.010.

[14] Valverde L, Rosa F, del Real AJ, Arce A, Bordons C. Modeling, simulation and experimental set-up of a renewable hydrogen-based domestic microgrid. Int J Hydrogen Energy 2013;38:11672-84. http://dx.doi.org/10.1016/ j.ijhydene.2013.06.113.

[15] Ekanayake JB, Holdsworth L, Wu X, Jenkins N. Dynamic modeling of doubly fed induction generator wind turbines. Power Syst IEEE Trans 2003;18:803-9. http://dx.doi.org/ 10.1109/TPWRS.2003.811178.

[16] Verkinderen E, Imam B. A simplified dynamic model for mast design of H-Darrieus vertical axis wind turbines (VAWTs). Eng Struct 2015;100:564-76. http://dx.doi.org/10.1016/ j.engstruct.2015.06.041.

[17] Chen H-C, Qiu J-C, Liu C-H. Dynamic modeling and simulation of renewable energy based hybrid power systems. In: Electr util deregul restruct power technol 2008 DRPT 2008 third int conf; 2008. p. 2803-9. http://dx.doi.org/ 10.1109/DRPT.2008.4523887.

[18] Villalva MG, Gazoli JR, Filho ER. Comprehensive approach to modeling and simulation of photovoltaic arrays. Power Electron IEEE Trans 2009;24:1198-208. http://dx.doi.org/ 10.1109/TPEL.2009.2013862.

[19] Liu G, Nguang SK, Partridge A. A general modeling method for I-V characteristics of geometrically and electrically configured photovoltaic arrays. Energy Convers Manag 2011;52:3439-45. http://dx.doi.org/10.1016/ j.enconman.2011.07.011.

[20] Awasthi A, Scott K, Basu S. Dynamic modeling and simulation of a proton exchange membrane electrolyzer for hydrogen production. Int J Hydrogen Energy 2011;36:14779-86. http://dx.doi.org/10.1016/ j.ijhydene.2011.03.045.

[21] Raju M, Khaitan SK. System simulation of compressed hydrogen storage based residential wind hybrid power systems. J Power Sources 2012;210:303-20. http://dx.doi.org/ 10.1016/j.jpowsour.2012.02.050.

[22] Tremblay O, Dessaint L-A, Dekkiche A-I. A generic battery model for the dynamic simulation of hybrid electric vehicles. In: Veh power propuls conf 2007 VPPC 2007 IEEE; 2007. p. 284-9. http://dx.doi.org/10.1109/VPPC.2007.4544139.

[23] Colson CM, Nehrir MH. A review of challenges to real-time power management of microgrids. In: Power Energy Soc Gen Meet 2009 PES '09 IEEE; 2009. p. 1-8. http://dx.doi.org/10.1109/ PES.2009.5275343.

[24] Valverde L, Bordons C, Rosa F. Integration of fuel cell technologies in renewable-energy-based microgrids optimizing operational costs and durability. Ind Electron IEEE Trans 2015. http://dx.doi.org/10.1109/TIE.2015.2465355. PP:1.

[25] Pereira M, Limon D, Munoz de la Pena D, Valverde L, Alamo T. Periodic economic control of a nonisolated microgrid. Ind Electron IEEE Trans 2015;62:5247-55. http:// dx.doi.org/10.1109/TIE.2015.2404815. 
[26] Bordons C, García-Torres F, Valverde L. Gestión Óptima de la Energía en Microrredes con Generación Renovable. Rev Iberoam Automática E Inform Ind RIAI 2015;12:117-32. http://dx.doi.org/10.1016/j.riai.2015.03.001.

[27] Amjady N, Keynia F, Zareipour H. Short-term load forecast of microgrids by a new bilevel prediction strategy. Smart Grid IEEE Trans 2010;1:286-94. http://dx.doi.org/10.1109/ TSG.2010.2078842.

[28] Yuan Y, Sun C, Li M, Choi SS, Li Q. Determination of optimal supercapacitor-lead-acid battery energy storage capacity for smoothing wind power using empirical mode decomposition and neural network. Electr Power Syst Res 2015;127:323-31. http://dx.doi.org/10.1016/j.epsr.2015.06.015.

[29] Petrollese M, Valverde L, Cocco D, Cau G, Guerra J. Real-time integration of optimal generation scheduling with MPC for the energy management of a renewable hydrogen-based microgrid. Appl Energy 2016;166:96-106. http://dx.doi.org/ 10.1016/j.apenergy.2016.01.014.

[30] Zhou K. Optimal energy management strategy and system sizing method for stand-alone photovoltaic-hydrogen systems. Int J Hydrogen Energy 2008;33:477-89. http:// dx.doi.org/10.1016/j.ijhydene.2007.09.027.

[31] Ghosh P, Emonts B, Janßen H, Mergel J, Stolten D. Ten years of operational experience with a hydrogen-based renewable energy supply system. Sol Energy 2003;75:469-78. http:// dx.doi.org/10.1016/j.solener.2003.09.006.

[32] Ipsakis D, Voutetakis S, Seferlis P, Stergiopoulos F, Elmasides C. Power management strategies for a stand-alone power system using renewable energy sources and hydrogen storage. Int J Hydrogen Energy 2009;34:7081-95. http:// dx.doi.org/10.1016/j.ijhydene.2008.06.051.

[33] Ou T-C, Hong C-M. Dynamic operation and control of microgrid hybrid power systems. Energy 2014;66:314-23. http://dx.doi.org/10.1016/j.energy.2014.01.042.

[34] Kyriakarakos G, Dounis AI, Arvanitis KG, Papadakis G. A fuzzy logic energy management system for polygeneration microgrids. Renew Energy 2012;41:315-27. http://dx.doi.org/ 10.1016/j.renene.2011.11.019.

[35] Stewart EM, Lutz AE, Schoenung S, Chiesa M, Keller JO, Fletcher J, et al. Modeling, analysis and control system development for the Italian hydrogen house. Int J Hydrogen Energy 2009;34:1638-46. http://dx.doi.org/10.1016/ j.ijhydene.2008.12.008.

[36] Vosen S. Hybrid energy storage systems for stand-alone electric power systems: optimization of system performance and cost through control strategies. Int J Hydrogen Energy 1999;24:1139-56. http://dx.doi.org/10.1016/S0360-3199(98) 00175-X.

[37] Valverde L, Bordons C, Rosa F. Power management using model predictive control in a hydrogen-based microgrid. In: IECON 2012-38th Annu Conf IEEE Ind Electron Soc; 2012. p. 5669-76. http://dx.doi.org/10.1109/IECON.2012.6389059.

[38] Khalid M, Savkin AV. A model predictive control approach to the problem of wind power smoothing with controlled battery storage. Renew Energy 2010;35:1520-6. http:// dx.doi.org/10.1016/j.renene.2009.11.030.

[39] Pereira M, Limon D, Alamo T, Valverde L, Bordons C. Economic model predictive control of a smartgrid with hydrogen storage and PEM fuel cell. In: Ind Electron Soc IECON 2013-39th Annu Conf IEEE; 2013. p. 7920-5. http:// dx.doi.org/10.1109/IECON.2013.6700456.

[40] Hooshmand A, Asghari B, Sharma R. A novel cost-aware multi-objective energy management method for microgrids. In: Innov smart grid technol (ISGT), 2013 IEEE PES; 2013. p. 1-6. http://dx.doi.org/10.1109/ISGT.2013.6497882.

[41] Salazar J, Tadeo F, Valverde L. Predictive control of a renewable energy microgrid with operational cost optimization. In: Ind Electron Soc IECON 2013-39th Annu Conf IEEE; 2013. p. 7950-5. http://dx.doi.org/10.1109/ IECON.2013.6700461. 